Research Article

\title{
Mexican Sage (Salvia officinalis) Extraction Using Factorial Design and Its Effect on Chemical and Antibacterial Properties
}

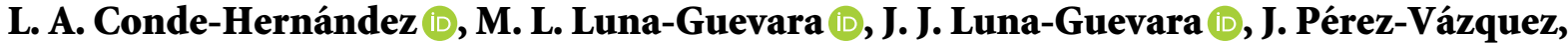 \\ and R. J. Aranda-García $\mathbb{D}$
}

Faculty of Chemical Engineering, Benemérita Universidad Autónoma de Puebla, Av. San Claudio and 18 Sur, Ciudad Universitaria, 72570 Puebla, Mexico

Correspondence should be addressed to M. L. Luna-Guevara; maria.luna@correo.buap.mx

Received 23 January 2021; Revised 3 March 2021; Accepted 9 March 2021; Published 23 March 2021

Academic Editor: Ajaya Kumar Singh

Copyright $\odot 2021$ L. A. Conde-Hernández et al. This is an open access article distributed under the Creative Commons Attribution License, which permits unrestricted use, distribution, and reproduction in any medium, provided the original work is properly cited.

\begin{abstract}
The essential oils (EOs) extracted by hydrodistillation (HYDRO) and steam distillation (SD) from Mexican Salvia officinalis L were analyzed for yield, chemical composition (GC-MS), particle morphology (SEM), antioxidant activity (ABTS), and antibacterial activity against Enterobacter agglomerans, Citrobacter freundii, Salmonella sp, E. coli, and Pseudomonas aeruginosa. The influence of the factors (method, quantity, and sample) was evaluated using a $2^{3}$ full factorial design, Pareto chart, normal probability plot, main effects, and interaction plots in variance analysis on yield and antioxidant activity. The quantity, methods, sample, and the methods $\times$ sample and methods $\times$ quantity interactions were the most significant factors on yield (\%). The sample, methods, and quantity $\times$ sample interaction were significant for antioxidant activity. EO yields were between 0.35 and $1.27(\% \mathrm{w} / \mathrm{w})$, and the highest value was obtained by the HYDRO method using $50 \mathrm{~g}$ of whole sage leaves. The antioxidant activity values were in the range of 2.35 to $3.44 \mathrm{mg}$ Trolox equivalent/g. Camphor, limonene, camphene, and caryophyllene were the main compounds identified. Micrographs of sage leaves showed relevant changes in the structure after extraction. The antibacterial activity was confirmed with the inhibition diameter and inhibition percentage of all bacteria, and P. aeruginosa was the most resistant bacteria. Finally, S. officinalis EO potentials can be considered an alternative natural preservative for the food and pharmaceutical industries.
\end{abstract}

\section{Introduction}

Essential oils (EOs) are called ethereal or volatile oil and they have been widely used in traditional medicine. These compounds are extracted from the various parts of the plants and mostly used as food flavors [1]. The EOs are complex mixtures of several low-molecular-weight and volatile compounds, such as isoprenoids, mainly mono- and sesquiterpenes, short-chain alcohols, aldehydes, and simple phenols. The EOs are produced and secreted by glandular trichomes, specialized secretory tissues diffused onto the surface of plant organs, particularly flowers and leaves [2].

Sage species are generally known for their multiple pharmacological effects, including antibacterial, antiviral, antioxidative, anti-inflammatory, antidiabetic, cardiovascular, antitumor, and anticancer [3]. These beneficial activities are positively related to phenolic compounds, such as phenolic diterpenoids (carnosic acid, carnosol, and rosmanol), phenolic acids (caffeic acid, rosmarinic acid, and ferulic acid), and flavonoids (luteolin derivatives and apigenin derivatives) $[4,5]$.

Within the main components of sage essential oil are 1,8cineole (64.3\%), $\alpha$-pinene (6.5\%), and camphor (6.1\%) [6]. Damyanova et al. [7] found that the main compounds of the Bulgaria sage essential oil are $\alpha$-thujone (26.68\%), (E)- $\beta$-caryophyllene (7.47\%), 1,8-cineole (7.19\%), $\alpha$-humulene (6.11\%), $\beta$-pinene (5.44\%), and camphor (4.84\%).

The antioxidant activity of sage EO makes them useful as natural preservatives in food, cosmetics, and pharmaceutical 
products [8]. These properties depend on EO's chemical composition that is strongly influenced by environmental, genetic, and botanical factors and harvest time [9].

Essential oils and extracts of $S$. officinalis are generally recognized as safe (GRAS) for use as spices, other natural seasonings, and flavorings, according to the Food and Drug Administration [10]. As well, this essential oil has been evaluated for its antibacterial effect, and it was found much better in comparison with most known antibiotics, especially against resistant bacteria [11].

Nevertheless, there are no reports regarding yield, antioxidant and antibacterial activities, composition, and micrographs from Mexican sage essential oils. Based on these considerations, we essentially aimed to evaluate the most effective parameter (method, quantity, and sample) using the factorial design and analysis of variance (ANOVA) for the extraction process. In addition, the essential oils of Mexican Salvia officinalis were characterized, and their antioxidant and antibacterial activities were analyzed.

\section{Materials and Methods}

2.1. Plant Material. The sage (S. officinalis) was grown in Atlixco, Puebla, Mexico, and the dried leaves were purchased from a local herbal shop (brand name "Sagrado Corazón de Jesús”).

2.2. Sample Preparation. The whole and ground dried leaves of sage were used for the essential oil extraction process. The pulverized sample was sieved $(420 \pm 25 \mu \mathrm{m})$ using a Keck Sieve Shaker kit (Cole Parmer, Vernon Hills, IL, USA) while the dried samples were packed into plastic bags, sealed under vacuum, protected from light, and stored at room temperature until use.

2.3. Essential Oil Extraction. Two processes (steam distillation and hydrodistillation), two quantities (25 and $50 \mathrm{~g}$ ), and two presentations (whole and ground) of sage leaves were used. The obtention processes were conducted in a Clevenger-type distillation apparatus. Moreover, the extraction time for each experiment was $120 \mathrm{~min}$ and the obtained essential oils were stored at $4^{\circ} \mathrm{C}$ until further tests [12]. All extractions were done in triplicate.

2.4. Yield. This parameter was calculated by the following equation:

$$
\% \text { yield }=\frac{\text { mass of essential oil }(\mathrm{g})}{\text { mass of dry leaves }(\mathrm{g})} * 100 \text {. }
$$

The essential oil with the highest yield was chosen, to carry out the chemical composition and antimicrobial activity.

2.5. Antioxidant Activity. The antioxidant activity was analyzed by the ABTS (2,2'-azino-bis 3-ethylbenzothiazoline- 6-sulfonate) (Sigma-Aldrich, St. Louis, USA) method [13]. The $\mathrm{ABTS}^{\bullet+}$ radical was obtained by reacting the ABTS $(7 \mathrm{mM})$ with potassium persulfate $(2.45 \mathrm{mM})$ (SigmaAldrich, St. Louis, USA) for $16 \mathrm{~h}$ at room temperature. Once the radical $\mathrm{ABTS}^{\bullet+}$ was formed, it was diluted with ethanol to obtaining an initial absorbance (Ai) of $0.7 \pm 0.02$, measured at $754 \mathrm{~nm}$ (Thermo Scientific ${ }^{\mathrm{TM}}$ GENESYS $^{\text {тм }} 20$, Visible Spectrophotometer). The antioxidant capacity was measured by placing $3920 \mu \mathrm{L}$ of the $\mathrm{ABTS}^{\bullet+}$ radical-ethanol solution in a quartz spectrophotometer cell and $80 \mu \mathrm{L}$ of essential oil (dissolved in ethanol, used as blank), thoroughly mixed, allowed to react for $7 \mathrm{~min}$, and the final absorbance was measured (Af). To calculate the antioxidant activity, Trolox (T) (6-hydroxy2,5,7,8 tetramethylchromane-2-carboxylic acid) was used in concentrations from 0 to $0.2 \mathrm{mg} / \mathrm{mL}$. The standard curve was inhibition $(\%)=387.13(\% / \mathrm{mg}$ Trolox $/ \mathrm{mL}) * \mathrm{C}(\mathrm{mg}$ Trolox $/ \mathrm{mL})+3.256 \%\left(R^{2}=0.996\right)$, and the antioxidant activity in oils was expressed as $\mathrm{mg}$ Trolox equivalent/g essential oil (mg TE/g EO).

2.6. Compound Identification. The volatile chemical compounds were characterized by gas chromatography/mass spectrometry (GC-MS). A gas chromatograph equipped with a 5975 quadrupole mass selective detector (Agilent Technologies 6850N GC, Santa Clara, CA, USA) and an HP5-MS column (30 $\mathrm{m}$ in length and $0.25 \mathrm{~mm}$ in diameter) was required. Conditions for analysis were as follows: helium as carrier gas at a flow rate of $15.5 \mathrm{~mL} / \mathrm{min}$, an injector temperature of $250^{\circ} \mathrm{C}$, an injection volume of $1 \mu \mathrm{L}$, a split ratio of $10: 1$, and programmed temperature starting at $60^{\circ} \mathrm{C}$ and increasing at $4^{\circ} \mathrm{C} / \mathrm{min}$ until reaching $250^{\circ} \mathrm{C}$. The ionization energy was $70 \mathrm{eV}$. The scanning mass range was $43-350 \mathrm{~m} / z$. Identification of the volatile compounds was performed by comparing their mass spectra with mass spectra of the NIST (National Institute of Standards and Technology) database library and information published in the literature [14].

2.7. Scanning Electron Microscopy (SEM). The morphology of samples exposed to the hydrodistillation process was examined using a JEOL JSM-6610LV scanning electron microscope (Tokyo, Japan). A probe, attached to the microscope, was used to perform the chemical analysis by the dispersive X-ray energy technique. All samples were examined under a high vacuum and acceleration voltage of $20 \mathrm{kV}$.

2.8. Antibacterial Activity. The antibacterial properties were ascertained in triplicate against Enterobacter agglomerans, Citrobacter freundii, Salmonella sp, E. coli, and Pseudomonas aeruginosa. Gram-negative bacteria were isolated from foods and identified using their colonial morphology on selective media (MacConkey, Brilliant Green agar, and Cetrimide agar), Gram staining, and biochemical tests (IMViC). Automated system VITEK (bioMerieux, Mexico) and 16S 
rRNA gene partial sequencing were used to confirm the identification of bacterial genera. The $16 \mathrm{~S}$ rRNA partial gene sequences were compared to sequences deposited in the GenBank database of the National Center for Biotechnology Information (NCBI) by using the Basic Local Alignment Search Tool (BLAST) algorithm. The bacterial strains were stored in Trypticasein Soy Broth (TSB) with 20\% glycerol at $-80^{\circ} \mathrm{C}$. The bacteria were cultivated in TSB at optimal growth conditions overnight $\left(24 \mathrm{~h}\right.$ at $\left.37^{\circ} \mathrm{C}\right)$, and an aliquot was again transferred to TSB and grown at $37^{\circ} \mathrm{C}$ with stirring. Suspensions containing approximately $10^{7} \mathrm{CFU} / \mathrm{mL}$ were used for antimicrobial activity assays.

In vitro antibacterial activity of the essential oil of sage was evaluated by cup-plate method, and a cup of $9 \mathrm{~mm}$ diameter was made using a sterile cork borer in the center of the inoculated plate of Trypticasein Soy Agar. $30 \mu \mathrm{L}$ of sage extract concentrations $(0,25,50,75$, and $100 \%)$ was added to each cup. They were agitated with a stir and PBS (saline buffer) was prepared. The inoculated plates were incubated for $24 \mathrm{~h}$ at $37^{\circ} \mathrm{C}$ [15].

After incubation, the mean inhibition zone diameter for each concentration was measured in millimeters, and all the studies were performed in triplicate. The blank cup containing $30 \mu \mathrm{L}$ of PBS was used as a negative control. The results were expressed as inhibition diameters $(\mathrm{mm})$ and the percentage of inhibition halo calculated according to the following equation:

$$
\text { inhibitory }(\%)=\frac{D}{\mathrm{AD}} * 100,
$$

where $D$ corresponds to the diameter of the inhibition halo of the microbial agent exposed to different concentrations of the antimicrobial extract and $\mathrm{AD}$ was the diameter of the antibiotic inhibition halo (nalidixic acid, $45 \mathrm{~mm}$ ).

2.9. Factorial Design of Experiments. The factorial design describes which factor shows more impact and influences over the other factors [16]. A $2^{3}$ factorial design with three factors at two levels was employed (Table 1), and the factors and interaction effects, coefficients of the model, normal probability plot, and Pareto chart on essential oil yield (\%) and antioxidant activity were analyzed. The order of the experiments was randomized to avoid systematic errors. The results were analyzed with the Minitab 18 software, and the main effects and interactions between factors were determined.

\section{Results and Discussion}

3.1. Yield. The coded values of variables with the responses (yield and antioxidant activity) are mentioned in Table 2. The lowest yield was $0.35 \%(\mathrm{w} / \mathrm{w})$ when extracting $25 \mathrm{~g}$ of ground sage using the SD method. The highest (1.27\%) was obtained by the HYDRO method using $50 \mathrm{~g}$ of the whole sample. The result obtained in this work is consistent with those reported by Baydar et al. [17] (1.43-3.24\%), who used Clevenger-type apparatus for $3 \mathrm{~h}$. Alike, Miguel et al. [6] obtained yields of sage oil of
TABLE 1: Factors and levels used in the factorial design.

\begin{tabular}{lcc}
\hline Factor & Low level $(-1)$ & High level $(+1)$ \\
\hline Method (A) & HYDRO & SD \\
Quantity (B) & $25 \mathrm{~g}$ & $50 \mathrm{~g}$ \\
Sample (C) & Ground & Whole \\
\hline
\end{tabular}

$2.0-2.1 \%(\mathrm{v} / \mathrm{w})$ and the extraction was performed with the hydrodistillation method, and Russo et al. [18] found yields between 0.55 and $2.2 \%$ with 18 different types of sage essential oils of different collection sites in Italy, using hydrodistillation for $3 \mathrm{~h}$. Kammoun El Euch et al. [19] reported, for the same method and time, a yield of $1.03 \%(\mathrm{w} / \mathrm{w})$, to sage from Tunisia.

The use of whole sage leaves improved oil extraction compared to the powdered leaves; moreover, higher yields of essential oil were observed using $50 \mathrm{~g}$ of sample. Nonetheless, doubling the quantity of raw material did not result in double the yield.

According to the full $2^{3}$ factorial design, the main factors and interaction effects on yield are presented in Figure 1. Figure 1(a) shows the main effects of the methods, quantity, and sample on the yield (\%).When the largest vertical line changed from level -1 to level +1 , it shows the main variation on yield (\%).

From the interaction plots (Figure 1(b)), the nonparallel lines between the lowest $(-1)$ and highest $(+1)$ level values imply that there was a two-way interaction with different slopes. The steeper line (highest gradient) and the largest difference between points indicated the main effect or interaction [20]. Also, these figures illustrate the interactions (positive and negative) between the methods, quantity, and sample regarding yield (\%). The method$s \times$ quantity and methods $\times$ sample plots (Figure 1 ) describe a strong interaction between both factors. Regarding the methods $\times$ quantity interaction, the effect of quantity was significant at the low-level method. Likewise, the maximum $\%$ yield $(1.27 \%)$ was achieved at the low-level method and high-level quantity. This value was higher than that reported for Algeria's sage, processed by hydrodistillation $(0.9 \% \mathrm{w} / \mathrm{w})$ [21]. The sample effect was significant at the low-level method, which is shown in the methods $\times$ sample plot.

The maximum \% yield was observed at the high-level sample with the low-level method and the high-level quantity. However, the quantity $\times$ sample plot describes a weaker interaction effect between the factors.

Therefore, the essential oil yield can be expressed with the following model with an adjusted square correlation coefficient $R^{2}$ of $94.88 \%$, fitting the statistical model quite well:

$$
\begin{aligned}
\text { yield }= & 0.1331-0.2798^{*} A+0.01716^{*} B+0.0333^{*} C \\
& +0.00344 A^{*} B-0.0511 A^{*} C+0.00200 B^{*} C .
\end{aligned}
$$

The negative and positive signs of each coefficient were based on each independent variable effect on yield, while the magnitude of the coefficient denoted the degree of significance of each independent variable. The order of significance 
TABLE 2: Design matrix for yield and antioxidant activity.

\begin{tabular}{lccccc}
\hline Runs & Methods (A) & Quantity (B) & Sample (C) & Yield (\%) & Antioxidant activity (mg TE/g EO) \\
\hline 1 & -1 & -1 & -1 & 0.61 & 3.21 \\
2 & 1 & -1 & -1 & 0.35 & 3.44 \\
3 & -1 & 1 & -1 & 0.93 & 3.11 \\
4 & 1 & 1 & -1 & 0.79 & 3.35 \\
5 & -1 & -1 & 1 & 0.90 & 2.35 \\
6 & 1 & -1 & 1 & 0.39 & 2.83 \\
7 & -1 & 1 & 1 & 1.27 & 2.61 \\
8 & 1 & 1 & 0.98 & 2.94 \\
\hline
\end{tabular}

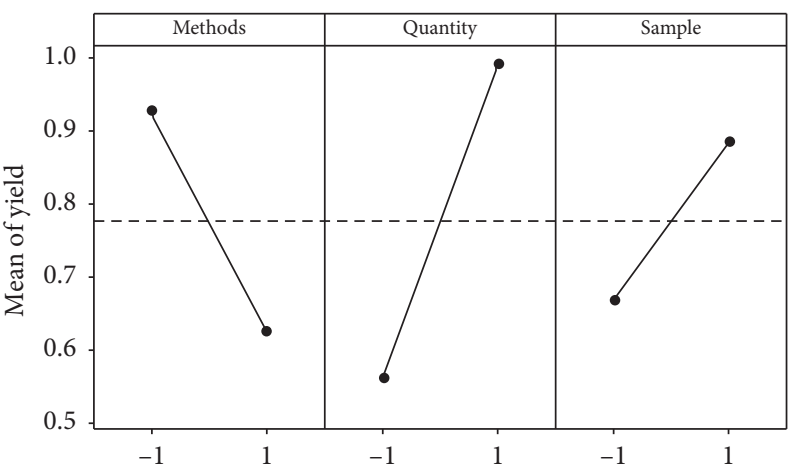

(a)

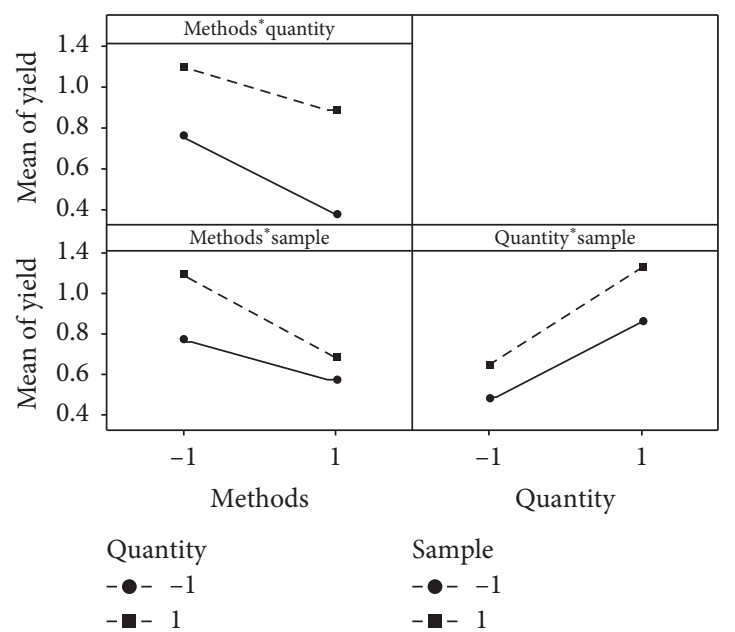

(b)

Figure 1: Plots of (a) main effects and (b) interaction effects for yield (\%).

based on magnitude was in good agreement with the resulting sequence of the Pareto chart [22].

The ABC (methods, quantity, and sample) effect was insignificant when it was compared with other effects, so it was not included in the model equation.

The normal probability plot of the standardized effects $(P=0.05)$ showed the significance of each factor and their interactions on yield (Figure 2(a)). This plot can be separated into two regions: the region with above $50 \%$ indicated as positive coefficients $(\mathrm{BC}, \mathrm{AB}, \mathrm{C}$, and $\mathrm{B})$ and the region with below $50 \%$ indicated as negative coefficients (AC and $\mathrm{A}$ ). Based on the Pareto chart (Figure 2(b)), the sequence of the significant terms and the main interaction effects with respect to the \% yield had the following order: $\mathrm{B}$ (quantity) $>\mathrm{A}$ (method) $>\mathrm{C}$ (sample) $>\mathrm{AC}$ (method and sample) $>\mathrm{AB}$ (method and quantity) $>\mathrm{BC}$ (quantity and sample).

3.2. Antioxidant Activity. Table 2 shows the antioxidant activity of sage oils obtained by both extraction methods, and the highest activity ( $3.44 \pm 0.17 \mathrm{mg} \mathrm{TE} / \mathrm{g}$ of EO) was observed with $25 \mathrm{~g}$ of ground leaf using the SD method. Conversely, the HYDRO method reported the lowest value $(2.35 \pm 0.05 \mathrm{mg}$ TE/ $\mathrm{g}$ EO) using $25 \mathrm{~g}$ of whole leaf. These results are similar to those reported by Carnerio et al. [23], who mentioned the values of 14.46 and $36.00 \mathrm{mg}$ Trolox/g in Eugenia klotzschiana Berg
(Myrtaceae) oil, using hydrodistillation $(2 \mathrm{~h})$ and a modified Clevenger-type apparatus. Ribeiro-Santos et al. [24] analyzed the antioxidant activity of four commercial essential oils: Ocimum basilicum, Cinnamomum cassia, Cinnamomum zeylanicum, and Rosmarinus officinalis with results of 1.81, 4.17, 474.80, and $2.75 \mathrm{mg}$ Trolox/g, respectively. Likewise, CondeHernández et al. [25, 26] evaluated rosemary (Rosmarinus officinalis) and pepper leaf (Piper autirum) essential oils obtained by steam distillation, and they reported antioxidant activity values of $2.7 \mathrm{mg}$ Trolox $/ \mathrm{g}$ and $1.8 \mathrm{mg}$ Trolox $/ \mathrm{g}$, respectively. Our results about the antioxidant activity are consistent with previous studies, which have claimed that EO contains pigmented and hydrophilic antioxidant compounds. These oils reflect better activity with ABTS than DPPH radical. For this reason, the ABTS test results were chosen to be evaluated in this study. Moreover, the antioxidant efficiency of sage essential oils has been attributed mainly to its majoritarian components, such as monoterpenes and sesquiterpenes hydrocarbons (in this work, 65.5 and 5.58\%, respectively).

This antioxidant activity is related to the complex mixture of essential oils, which are constituted by different mono- and sesquiterpenes, and they present synergistic effects between them [24, 27]. Therefore, the antioxidant activity results are a good indicative that sage essential oils could be a potential source of natural antioxidant foods. 


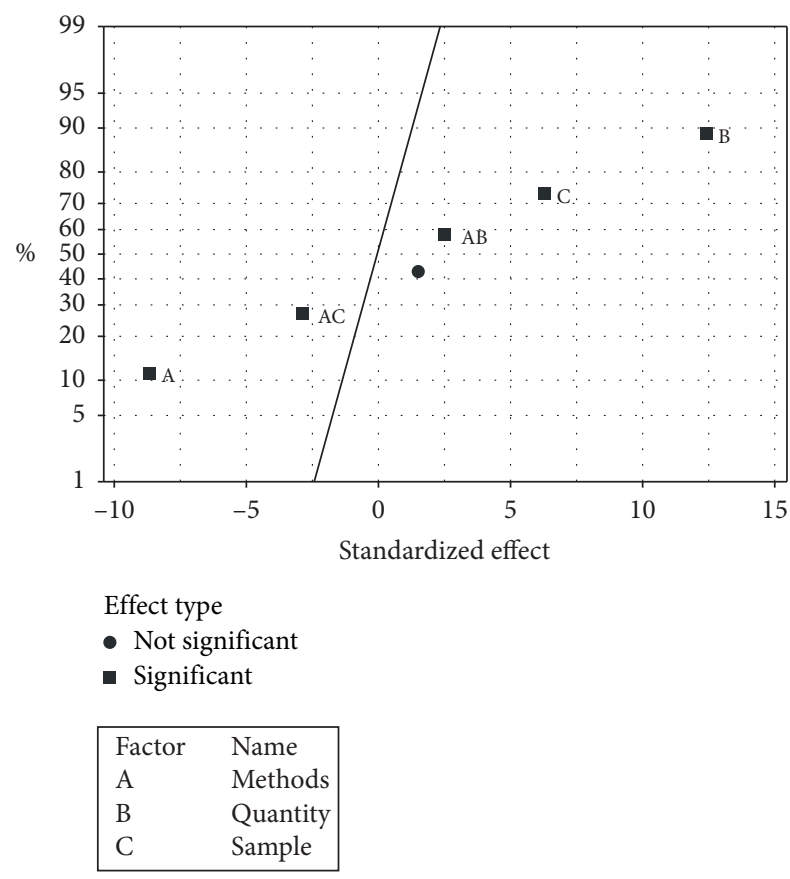

(a)

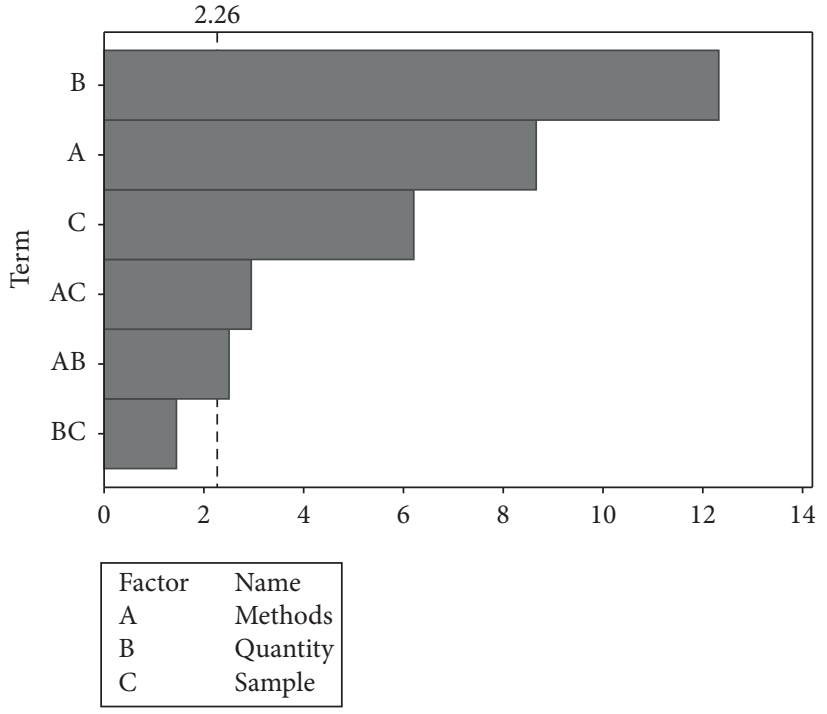

(b)

Figure 2: (a) Normal probability plot of the standardized effects at $P=0.05$ and (b) Pareto chart of the significance rank of main effects and interaction effects of extraction factors on yield.

According to the factorial design, Figure 3(a) shows the main effects of the three factors (methods, quantity, and sample) on antioxidant activity; specifically, the quantity main effect was not significant.

In another way, Figure 3(b) illustrates that the methods $\times$ quantity and methods $\times$ sample plots describe a weaker interaction effect between both factors on antioxidant activity. Based on the methods $\times$ quantity plot, the maximum antioxidant activity was observed at the highlevel method (SD) and high-level quantity $(50 \mathrm{~g})$. Meanwhile, the methods $\times$ sample plot indicates that the maximum antioxidant activity was achieved at the high-level method (SD) and low-level sample (ground). As well, the quantity $\times$ sample plot describes a stronger interaction effect between both factors.

The antioxidant activity is expressed with the next model $\left(R^{2}\right.$ adj $\left.=94.22 \%\right)$; specifically, the effect of $\mathrm{ABC}$ interaction (methods, quantity, and sample) was not significant; therefore, it was not included in the next equation:

$$
\begin{aligned}
\text { antioxidant activity }= & 2.9095+0.2092^{*} A+0.00189^{*} B \\
& -0.5039^{*} C-0.00133 A^{*} B \\
& +0.0433 A^{*} C+0.00550 B^{*} C .
\end{aligned}
$$

The plot of normal probability (Figure 4(a)) shows the standardized effects on antioxidant activity: the regions with positive coefficients (BC and A) and negative coefficient (C). The factors and interactions surrounded with a circle were not significant $(\mathrm{AC}, \mathrm{B}$, and $\mathrm{AB}$ ), while those are denoted with a square were significant.
According to the Pareto chart (Figure 4(b)), the sequence of the significant terms and main interaction effects on the antioxidant activity was as follows: $\mathrm{C}$ (sample) $>\mathrm{A}$ (method) $>\mathrm{BC}$ (quantity and sample) $>\mathrm{AC}$ (method and sample) $>\mathrm{B}$ (quantity) $>\mathrm{AB}$ (method and quantity). Finally, all main effects (single effects) and two-factor interactions were not aliased with any other main effect or two-factor interactions, which is reported similarly by Cacua et al. [28].

\subsection{Analysis of Variance for Yield and Antioxidant Activity.} The ANOVA results of yield (\%) and antioxidant activity are shown in Tables 3 and 4, respectively. The sum of the squares used to estimate factors and Fisher's $F$ ratios (defined as the ratio of mean square effect and the mean square error) and $P$ values (defined as the level of significance leading to the rejection of the null hypothesis) were also represented [29]. Table 3 shows that the studied factors (methods, quantity, and sample) and their 2-way interactions (methods $\times$ quantity and method $\times$ sample) were statistically significant on yield. While the factors (methods and sample) and their 2-way interactions (methods-sample and quantity-sample) were statistically significant for antioxidant activity (Table 4).

3.4. Compound Identification. In this study, nineteen compounds were identified by a percentage of areas, using gas chromatography-mass spectrometry, for the Mexican sage EO that presented the highest yield (HYDRO-50-W) (Table 5). Oxygen-containing monoterpenes (65.6\%) constituted the majority fraction of the essential oils, with camphor (34.17\%), limonene (13.73\%), camphene (12.31\%), and sabinene (5.43\%), 


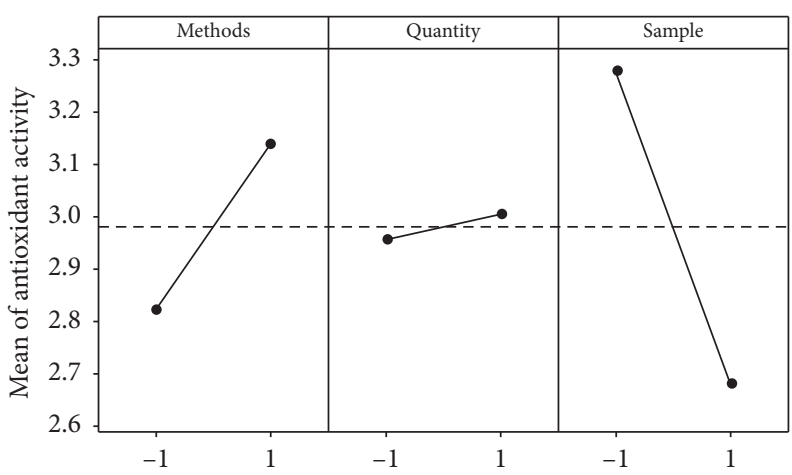

(a)

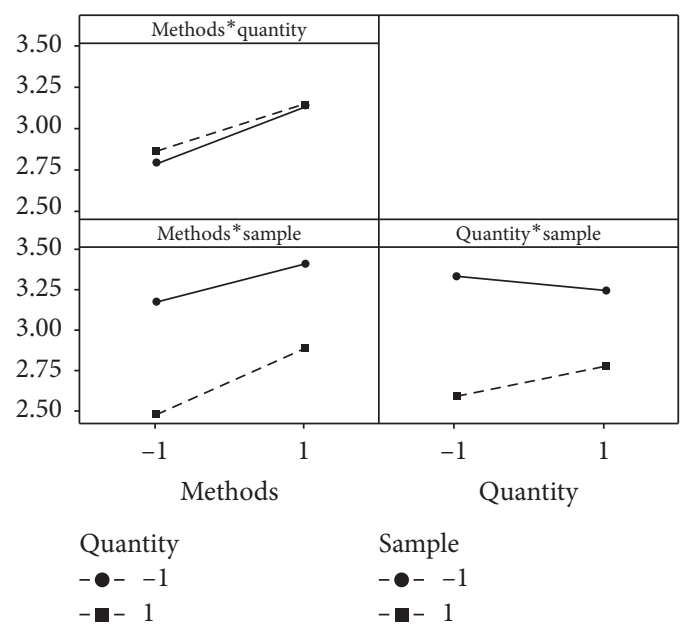

(b)

Figure 3: Plots of (a) main effects and (b) interaction effects for antioxidant activity.

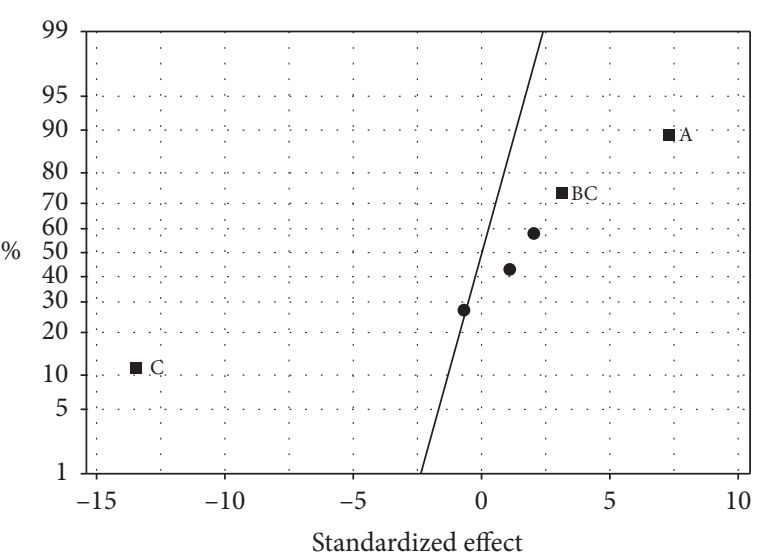

Effect type

- Not significant

- Significant

\begin{tabular}{|ll|}
\hline Factor & Name \\
A & Methods \\
B & Quantity \\
C & Sample \\
\hline
\end{tabular}

(a)

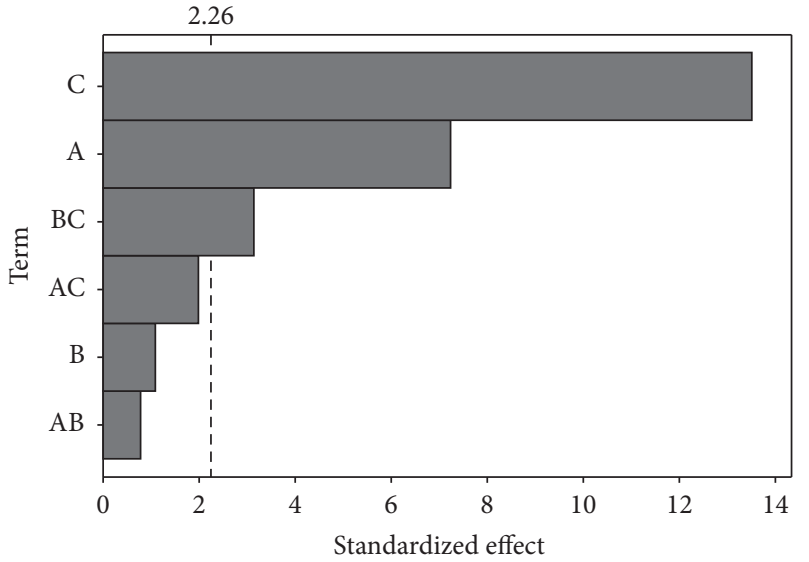

\begin{tabular}{|ll|}
\hline Factor & Name \\
A & Methods \\
B & Quantity \\
C & Sample \\
\hline
\end{tabular}

(b)

Figure 4: (a) Normal probability plot of the standardized effects at $P=0.05$ and (b) Pareto chart of the significance rank of main effects and interaction effects of extraction factors on antioxidant activity.

and an oxygen-containing sesquiterpene, caryophyllene (5.58\%). Camphor is being reported as the main compound in this work in similar percentages to what Kammoun El Euch et al. [19] reported.

Previous studies reported similar chemical composition for sage essential oil, $\alpha$-thujone, 1,8-cineole, and camphor, however in different quantities $[6,7,19,30,31]$.

Differences in the chemical composition of sage oil from different studies can be attributed to factors such as plant variety, country of origin, time of harvest, and climatic factors (such as climatic, seasonal, and geographical variations) [10, 25].
The compounds of Salvia officinalis for medical uses could be very promising for encouraging the population to consume these plants; besides, sage essential oils are substances generally recognized as safe.

3.5. Scanning Electron Microscopy (SEM). Micrographs of samples exposed to hydrodistillation using 25 and $50 \mathrm{~g}$ of whole leaves are shown in Figure 5. A smooth surface of the sample without treatment is shown. Sage structures treated with hydrodistillation show an irregular surface. Some holes 
TABle 3: Analysis of variance (ANOVA) for yield (\%).

\begin{tabular}{|c|c|c|c|c|c|}
\hline Source & Df & Sum of squares & Mean square & $F$ value & $P$ value \\
\hline Main effects & 3 & 1.28795 & 0.429318 & 88.98 & $\leq 0.001$ \\
\hline Methods & 1 & 0.36451 & 0.364514 & 75.55 & $\leq 0.001$ \\
\hline Quantity & 1 & 0.73574 & 0.735735 & 152.49 & $\leq 0.001$ \\
\hline Sample & 1 & 0.18771 & 0.187706 & 38.90 & $\leq 0.001$ \\
\hline 2-way interactions & 3 & 0.08126 & 0.027087 & 5.61 & 0.019 \\
\hline Methods $\times$ quantity & 1 & 0.02953 & 0.029532 & 6.12 & 0.035 \\
\hline Methods $\times$ sample & 1 & 0.04172 & 0.041718 & 8.65 & 0.016 \\
\hline Quantity $\times$ sample & 1 & 0.01001 & 0.010010 & 2.07 & 0.184 \\
\hline Residual error & 9 & 0.04342 & 0.004825 & & \\
\hline Pure error & 8 & 0.04049 & 0.005061 & & \\
\hline Total & 15 & 1.41264 & & & \\
\hline
\end{tabular}

TABLE 4: Analysis of variance (ANOVA) for antioxidant activity.

\begin{tabular}{|c|c|c|c|c|c|}
\hline Source & Df & Sum of squares & Mean square & $F$ value & $P$ value \\
\hline Main effects & 3 & 1.83252 & 0.61084 & 78.75 & $\leq 0.001$ \\
\hline Methods & 1 & 0.40642 & 0.40642 & 52.40 & $\leq 0.001$ \\
\hline Quantity & 1 & 0.00888 & 0.00888 & 1.15 & 0.312 \\
\hline Sample & 1 & 1.41722 & 1.41722 & 182.71 & $\leq 0.001$ \\
\hline 2-way interactions & 3 & 0.11004 & 0.03668 & 4.73 & 0.030 \\
\hline Methods $\times$ quantity & 1 & 0.00442 & 0.00442 & 0.57 & 0.470 \\
\hline Methods $\times$ sample & 1 & 0.02999 & 0.02999 & 3.87 & 0.081 \\
\hline Quantity $\times$ sample & 1 & 0.07563 & 0.07563 & 9.75 & 0.012 \\
\hline Residual error & 9 & 0.06981 & 0.00776 & & \\
\hline Pure error & 8 & 0.06316 & 0.00789 & & \\
\hline Total & 15 & 2.01238 & & & \\
\hline
\end{tabular}

TABle 5: Compounds identified by GC-MS in HYDRO-50-W sage essential oil.

\begin{tabular}{|c|c|c|c|c|c|}
\hline No. & Chemical compounds & Peak area $^{\mathrm{a}}(\%)$ & No. & Chemical compounds & Peak area $^{\mathrm{a}}(\%)$ \\
\hline 1 & $1 \mathrm{R}-\alpha$-Pinene & 2.25 & 11 & $\alpha$-Terpineol & 1.14 \\
\hline 2 & Camphene & 12.31 & 12 & Bornyl acetate & 0.75 \\
\hline 3 & $\beta$-Pinene & 1.81 & 13 & Myrtenyl acetate & 0.67 \\
\hline 4 & $\beta$-Myrcene & 0.9 & 14 & $\gamma$-Elemene & 1.22 \\
\hline 5 & Sabinene & 5.43 & 15 & Berbenone & 0.53 \\
\hline 6 & Limonene & 13.73 & 16 & Caryophyllene & 5.58 \\
\hline 7 & Terpinolene & 1.94 & 17 & $\alpha$-Caryophyllene & 0.89 \\
\hline 8 & 2-Carene & 2.28 & 18 & Germacrene D-4-ol & 2.4 \\
\hline 9 & Camphor & 34.17 & 19 & Spathulenol & 1.71 \\
\hline 10 & Borneol & 3.42 & & & \\
\hline
\end{tabular}

${ }^{a}$ Peak area (\%) of essential oil components. Components with percentage $\geq 0.5 \%$ are presented.

are also shown on the surface of sage. Most of the samples appear collapsed and ruptured. Such eruptions can facilitate the outpour of all jailed essential oil [32]. The extraction method resulted in clear physical changes in the structure.

3.6. Antibacterial Activity. The antimicrobial activity of S. officinalis essential oil was evaluated against five Gramnegative bacteria Pseudomonas, Enterobacter, Citrobacter, Salmonella, and E. coli. These bacteria were chosen as they are potentially pathogenic for humans and some of them are part of the group of total and fecal coliform. These microorganisms are often responsible for causing mild to severe illnesses that are transmitted via the fecal-oral route and have been detected in various foodstuffs and during food preparations [33].

The results show that $S$. officinalis essential oil has antimicrobial properties against studied microorganisms, and in all treatments, the inhibitory effect increased with the concentration of essential oil (Table 6). The diameters ranged from 11.25 to $24.25 \mathrm{~mm}$ corresponding to the genera Enterobacter. This same bacterium and Citrobacter showed higher sensitivity with inhibition percentages of $86.95 \%$ and $73.5 \%$, respectively. According to the analyses carried out by Alizadeh and Shaabanin [3], bacteria that showed inhibition diameters less than $7 \mathrm{~mm}$ were considered resistant to 


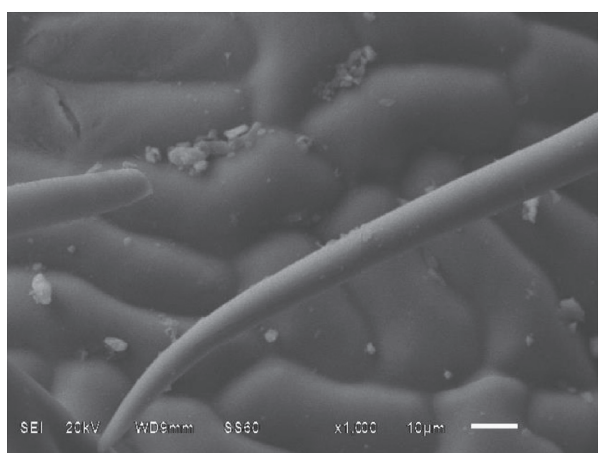

(a)

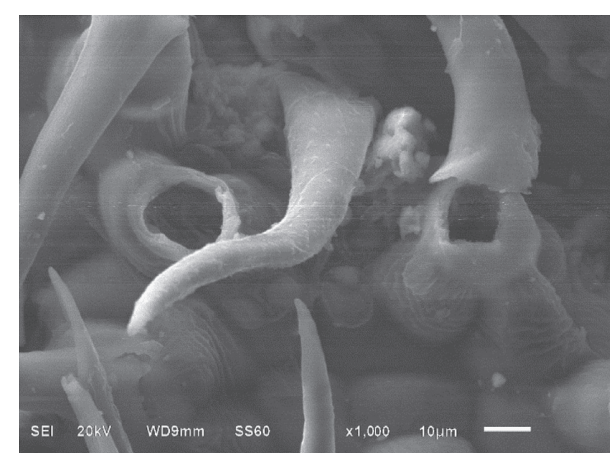

(b)

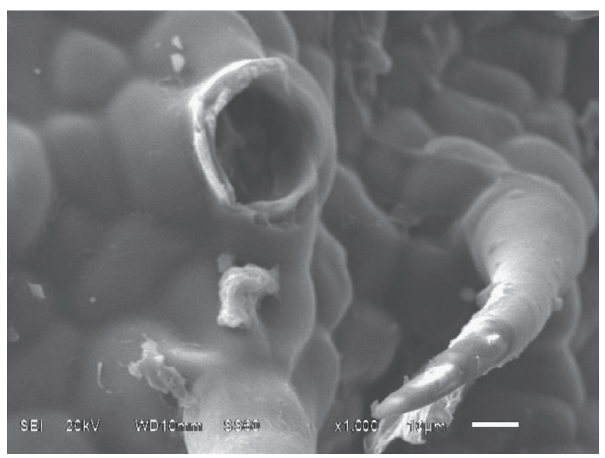

(c)

FIGURE 5: Micrographs of ground sage leaves. (a) Untreated, (b) HYDRO-25-W, and (c) HYDRO-50-W.

TABLE 6: Diameters and percentages of inhibition obtained with different concentrations of extracts from leaves of $S$. officinalis on different Gram-negative bacteria.

\begin{tabular}{|c|c|c|c|c|c|c|c|c|}
\hline \multirow{2}{*}{ Concent. Extract (\%) } & \multicolumn{4}{|c|}{ Diameter inhibition (mm) } & \multicolumn{4}{|c|}{ Inhibition percentages (\%) } \\
\hline & 25 & 50 & 75 & 100 & 25 & 50 & 75 & 100 \\
\hline Enterobacter agglomerans & $11.75 \pm 2.2$ & $11.25 \pm 1.3$ & $16.0 \pm 1.4$ & $24.25 \pm 0.8$ & $42.13 \pm 7.9$ & $40.34 \pm 4.5$ & $57.37 \pm 5.1$ & $86.95 \pm 2.0$ \\
\hline Citrobacter freundii & $13.0 \pm 3.7$ & $16.25 \pm 2.3$ & $19.0 \pm 1.2$ & $20.5 \pm 1.3$ & $46.61 \pm 1.0$ & $58.26 \pm 1.3$ & $68.13 \pm$ & 73.5 \\
\hline E. coli & $11.75 \pm 2.9$ & $14.75 \pm 1.7$ & $17.75 \pm 0.9$ & $19.25 \pm 3.8$ & $42.13 \pm 1.7$ & $52.88 \pm 6.1$ & $63.64 \pm$ & $69.0 \pm 1.35$ \\
\hline Salmonella sp & $11.50 \pm 1.0$ & $14.0 \pm 0.82$ & $15.50 \pm 0.98$ & $19.0 \pm 0.14$ & $41.23 \pm 3.6$ & $50.12 \pm 2.9$ & $55.58 \pm 3.5$ & $68.13 \pm 5.2$ \\
\hline
\end{tabular}

P. aeruginosa did not show inhibition (diameter inhibition $(\mathrm{mm})$ and inhibition percentages) with the analyzed concentrations of EO sage.

S. officinalis essential oil, while bacteria that showed diameters between 7 and $11 \mathrm{~mm}$ were dose-dependent and more than $11 \mathrm{~mm}$ were sensitive.

Even pathogens E. coli and Salmonella presented a similar sensitivity to $100 \%$ extracts. Regarding E. coli, inhibition percentages greater than $50 \%$ were observed with extracts of 50,75, and $100 \%$ (Table 6), and these results coincide with those obtained by López de Ávila et al. [34] who analyzed the antimicrobial properties of sage with various pathogens of relevance in food safety through cupplate and disk diffusion methods. Also, Pierozan et al. [35] evaluated the antimicrobial activity of the $S$. officinalis EO and obtained lower inhibition diameters than those attained in our study with values of $8 \mathrm{~mm}$ and $11 \mathrm{~mm}$ for E. coli and Salmonella, respectively. Ivanovic et al. [36] confirmed the activity against $E$. coli considering a MIC of $2,560 \mathrm{mg} / \mathrm{mL}$. The differences between the methods to analyze antimicrobial activity depend on several factors such as the volatile nature of the components of the essential oils, which may evaporate during inoculation and incubation and the abilities of dispersion of the EO in the culture medium [37]. However, the cup-plate method is a common technique used for the evaluation of antibacterial ability due to its simplicity and as small amounts of sample are required [15].

$P$. aeruginosa showed no inhibition with the analyzed concentrations of the $\mathrm{EO}$, and its resistance was verified by the study of Harfouch et al. [38], who used the disc diffusion method and extracts of Rosmarinus officinalis and Salvia officinalis. This resistance to multiple antimicrobial agents is caused by several factors such as low-permeability outer membrane, plasmid coding, and expression-specific multidrug efflux systems [39]. Mann et al. [40] reported that $P$. aeruginosa outer membrane is composed primarily of lipopolysaccharide. This forms a hydrophilic permeability 
barrier which provides protection against the effects of toxic agents.

Studies on the essential oils of Salvia officinalis show that antimicrobial potency is generally correlated to the chemical composition of the oil [41]. Pierozan et al. [35] consider that the antimicrobial activity of $S$. officinalis could be attributed to components as $\alpha$-thujone, 1,8-cineole, and camphor, and in this work, camphor is the main component of the essential oil (Table 5). Furthermore, it has been shown that the minority compounds of these EO can present a synergistic effect with the principal components.

The antimicrobial properties derived from S. officinalis are of great importance because they could be used as an alternative to the increasing resistance of traditional antibiotics against infections by pathogenic organisms [4].

\section{Conclusions}

In summary, these results demonstrate that the quantity, methods, sample, and the methods $\times$ sample and method$s \times$ quantity interactions were the most significant factors on yield (\%). However, the sample, methods extraction, and quantity $\times$ sample interaction were significant for antioxidant activity. The antioxidant activity of oil obtained by ground sage with hydrodistillation and steam distillation was significantly equal. The main compounds found in sage oils were camphor, limonene, camphene, and caryophyllene. Micrographs of the samples (obtained by SEM) undergone HYDRO indicated that the extraction method resulted in significant changes to the sage leaf structure. This founding can be useful for future research related to other plant extraction. Finally, the results obtained concluded that the sage EO inhibited the growth of E. coli, C. freundii, E. agglomerans, and Salmonella sp; however, P. aeruginosa was the most resistant bacteria.

\section{Data Availability}

The data used to support the findings of this study are included within the article.

\section{Conflicts of Interest}

The authors declare that they have no conflicts of interest.

\section{References}

[1] M. Irshad, M. Ali Subhani, S. Ali, and A. Hussain, "Biological importance of essential oils," in Essential Oils-Oils of Nature, H. El-Shemy, Ed., p. 1, IntechOpen, London, UK, 2020.

[2] M. Iriti, G. Colnaghi, F. Chemat, J. Smadja, F. Faoro, and F. A. Visinoni, "Histo-cytochemistry and scanning electron microscopy of Lavender glandular trichomes following conventional and microwave-assisted hydrodistillation of essential oils: a comparative study," Flavour and Fragrance Journal, vol. 21, no. 4, pp. 704-712, 2006.

[3] A. Alizadeh and M. Shaabani, "Essential oil composition, phenolic content, antioxidant, and antimicrobial activity in Salvia officinalis L. cultivated in Iran," Advances in Environmental Biology, vol. 6, no. 1, pp. 221-226, 2012.
[4] D. C. Costa, H. S. Costa, T. G. Albuquerque, F. Ramos, M. C. Castilho, and A. Sanches-Silva, "Advances in phenolic compounds analysis of aromatic plants and their potential applications," Trends in Food Science \& Technology, vol. 45, no. 2, pp. 336-354, 2015.

[5] E. Poulios, C. Giaginis, and G. K. Vasios, "Current advances on the extraction and identification of bioactive components of sage (Salvia spp.)," Current Pharmaceutical Biotechnology, vol. 20, no. 10, pp. 845-857, 2019.

[6] G. Miguel, C. Cruz, M. L. Faleiro et al., "Salvia officinalisL. essential oils: effect of hydrodistillation time on the chemical composition, antioxidant and antimicrobial activities," Natural Product Research, vol. 25, no. 5, pp. 526-541, 2011.

[7] S. Damyanova, S. Mollova, A. Stoyanova, and O. Gubenia, "Chemical composition of Salvia officinalis L. essential oil from Bulgaria," Ukrainian Food Journal, vol. 5, no. 4, pp. 695-700, 2016.

[8] B. Prakash, A. Kedia, P. K. Mishra, and N. K. Dubey, "Plant essential oils as food preservatives to control moulds, mycotoxin contamination and oxidative deterioration of agrifood commodities-potentials and challenges," Food Control, vol. 47, pp. 381-391, 2015.

[9] M. Maksimovic, D. Vidic, M. Milos, M. E. Solic, S. Abadzic, and S. Sijak-Yakovlev, "Effect of the environmental conditions on essential oil profile in two Dinaric Salvia species: S. brachyodon Vandas and S. officinalis L," Biochemical Systematics and Ecology, vol. 35, no. 8, pp. 473-478, 2007.

[10] Food and drug administration (FDA), Substances Generally Recognized as safe, Food and drug administration, Chennai, India, 2020, https://www.accessdata.fda.gov/scripts/cdrh/ cfdocs/cfcfr/CFRSearch.cfm?fr=582.20 2019.

[11] R. Khalil and Z. Li, "Antimicrobial activity of essential oil of Salvia officinalis L. collected in Syria," African Journal of Biotechnology, vol. 10, no. 42, pp. 8397-8402, 2011.

[12] C. Amadio, S. Farrando, and M. Zimmermann, "Effect of chitosan coating enriched with oregano essential oil on the quality of refrigerated meat hamburgers," Revista de la Facultad de Ciencias Agrarias, Universidad Nacional de Cuyo, vol. 51, no. 1, pp. 173-189, 2020.

[13] R. Re, N. Pellegrini, A. Proteggente, A. Annala, M. Yang, and C. Rice-Evans, "Antioxidant activity applying an improved ABTS radical cation decolorization assay," Free Radical Biology and Medicine, vol. 26, no. 9-10, pp. 1231-1237, 1999.

[14] R. P. Adams, Identification of Essential Oil Components by Ion Trap Mass Spectroscopy, Academic Press, San Diego, CA, USA, 1989.

[15] E. Escobar-Muciño, M. L. Luna-Guevara, M. E. RamosCassellis, G. G. Amador-Espejo, M. Castañeda-Lucio, and M. M. Arenas-Hernández, "Evaluation of process involved in the production of aromatic compounds in Gram-negative bacteria isolated from vanilla (Vanilla planifolia ex. Andrews) beans," Journal of Applied Microbiology, vol. 128, no. 4, pp. 1086-1098, 2020.

[16] Y. Safa and H. N. Bhatti, "Adsorptive removal of direct textile dyes by low cost agricultural waste: application of factorial design analysis," Chemical Engineering Journal, vol. 167, no. 1, pp. 35-41, 2011.

[17] H. Baydar, G. Özkan, S. Erbaş, and D. Altındal, "Yield, chemical composition and antioxidant properties of extracts and essential oils of sage and rosemary depending on seasonal variations," Acta Horticulturae, vol. 826, no. 826, pp. 383-390, 2009.

[18] A. Russo, C. Formisano, D. Rigano et al., "Chemical composition and anticancer activity of essential oils of 
Mediterranean sage (Salvia officinalis L.) grown in different environmental conditions," Food and Chemical Toxicology, vol. 55, pp. 42-47, 2013.

[19] S. Kammoun El Euch, D. B. Hassine, S. Cazaux, N. Bouzouita, and J. Bouajila, "Salvia officinalis essential oil: chemical analysis and evaluation of anti-enzymatic and antioxidant bioactivities," South African Journal of Botany, vol. 120, pp. 253-260, 2011.

[20] S. H. Chang, T. T. Teng, and N. Ismail, "Screening of factors influencing $\mathrm{Cu}$ (II) extraction by soybean oil-based organic solvents using fractional factorial design," Journal of Environmental Management, vol. 92, no. 10, pp. 2580-2585, 2011.

[21] T. Dob, T. Berramdane, D. Dahmane, T. Benabdelkader, and C. Chelghoum, "Chemical composition of the essential oil of Salvia officinalis from Algeria," Chemistry of Natural Compounds, vol. 43, no. 4, pp. 491-494, 2007.

[22] N. A. A. Halim, Z. Z. Abidin, S.-I. Siajam, C. G. Hean, and M. R. Harun, "Screening of factors influencing the yield of Citrus hystrix leaves essential oil extracted via pressurized hot water extraction based on resolution $\mathrm{V}$ fractional factorial design," Journal of Food Process Engineering, vol. 2020, Article ID e13531, 13 pages, 2020.

[23] N. S. Carneiro, C. C. F. Alves, J. M. Alves et al., "Chemical composition, antioxidant and antibacterial activities of essential oils from leaves and flowers of Eugenia klotzschiana Berg (Myrtaceae)," Anais da Academia Brasileira de Ciências, vol. 89, no. 3, pp. 1907-1915, 2017.

[24] R. Ribeiro-Santos, M. Andrade, N. R. De Melo et al., "Biological activities and major components determination in essential oils intended for a biodegradable food packaging," Industrial Crops and Products, vol. 97, pp. 201-210, 2017.

[25] L. A. Conde-Hernández, J. R. Espinosa-Victoria, A. Trejo, and J. Á. Guerrero-Beltrán, "CO 2-supercritical extraction, hydrodistillation and steam distillation of essential oil of rosemary (Rosmarinus officinalis )," Journal of Food Engineering, vol. 200, pp. 81-86, 2017.

[26] L. A. Conde-Hernández, J. R. Espinosa-Victoria, and J. Á. Guerrero-Beltrán, "Supercritical extraction of essential oils of Piper auritum and Porophyllum ruderale," The Journal of Supercritical Fluids, vol. 127, pp. 97-102, 2017.

[27] K. Prasad, "Chemical composition, antioxidant and antifungal activity of essential oils of pogostemon amaranthoides from (Raya-Bajeta valleys) pithoragarh, uttarakhand himalayas, India," Journal of Pharmacology and Clinical Research, vol. 6 , no. 4 , pp. 1-12, 2018.

[28] K. Cacua, R. Buitrago-Sierra, B. Herrera, F. Chejne, and E. Pabón, "Influence of different parameters and their coupled effects on the stability of alumina nanofluids by a fractional factorial design approach," Advanced Powder Technology, vol. 28, no. 10, pp. 2581-2588, 2017.

[29] N. Özbay, A. S. Yargiç, R. Z. Yarbay-Sahin, and E. Önal, "Full factorial experimental design analysis of reactive dye removal by carbon adsorption," Journal of Chemistry, vol. 2013, Article ID 234904, 13 pages, 2013.

[30] M. Bouaziz, T. Yangui, S. Sayadi, and A. Dhouib, "Disinfectant properties of essential oils from Salvia officinalis L. cultivated in Tunisia," Food and Chemical Toxicology, vol. 47, no. 11, pp. 2755-2760, 2009.

[31] A. P. L. Delamare, I. T. Moschen-pistorello, L. Artico, L. AttiSerafini, and S. Echeverrigaray, "Antibacterial activity of the essential oils of Salvia officinalis L. and Salvia triloba L. cultivated in South Brazil," Food Chemistry, vol. 100, no. 2, pp. 603-608, 2007.
[32] M. Gavahian, R. Farhoosh, A. Farahnaky, K. Javidnia, and F. Shahidi, "Comparison of extraction parameters and extracted essential oils from Mentha piperita L. using hydrodistillation and steam distillation," International Food Research Journal, vol. 22, no. 1, pp. 283-288, 2015.

[33] J. J. Luna-Guevara, M. M. P. Arenas-Hernandez, C. Martínez de la Peña, J. L. Silva, and M. L. Luna-Guevara, "The role of PathogenicE. Coliin fresh vegetables: behavior, contamination factors, and preventive measures," International Journal of Microbiology, vol. 2019, pp. 1-10, Article ID 2894328, 2019.

[34] L. M. López De Ávila, H. I. Castaño-Peláez, and C. E. MejíaGómez, "Efecto antimicrobiano del aceite esencial de Salvia officinalis sobre microrganismos patógenos transmitidos por alimentos," Actualidades Biológicas, vol. 35, no. 98, pp. 77-83, 2013.

[35] M. K. Pierozan, G. F. Pauletti, L. Rota et al., "Chemical characterization and antimicrobial activity of essential oils of Salvia L. species," Ciência e Tecnologia de Alimentos, vol. 29, no. 4, pp. 764-770, 2009.

[36] J. Ivanovic, D. Misic, I. Zizovic, and M. RistiC, "In vitro control of multiplication of some food-associated bacteria by thyme, rosemary and sage isolates," Food Control, vol. 25, no. 1, pp. 110-116, 2012.

[37] M. Fournomiti, A. Kimbaris, I. Mantzourani et al., "Antimicrobial activity of essential oils of cultivated oregano (Origanum vulgare), sage (Salvia officinalis), and thyme (Thymus vulgaris) against clinical isolates of Escherichia coli, Klebsiella oxytoca, and Klebsiella pneumoniae," Microbial Ecology in Health and Disease, vol. 26, no. 1, 7 pages, Article ID 23289, 2015.

[38] R. M. Harfouch, M. Darwish, W. Al-Asadi, A. F. Mohammad, N. M. Gharib, and M. Haroun, "Antibacterial activity of essential oils of Rosmarinus officinalis, Salvia officinalis and Anthemis nobilis widespread in the Syrian coast," Research Journal of Pharmacy and Technology, vol. 12, no. 7, pp. 3410-3412, 2019.

[39] H. P. Schweizer, "Efflux as a mechanism of resistance to antimicrobials in Pseudomonas aeruginosa and related bacteria: unanswered questions," Genetics and Molecular Research, vol. 2, no. 1, pp. 48-62, 2003.

[40] C. M. Mann, S. D. Cox, and J. L. Markham, "The outer membrane of Pseudomonas aeruginosa NCTC 6749 contributes to its tolerance to the essential oil of Melaleuca alternifolia (tea tree oil)," Letters in Applied Microbiology, vol. 30, no. 4, pp. 294-297, 2000.

[41] B. Tepe, E. Donmez, M. Unlu et al., "Antimicrobial and antioxidative activities of the essential oils and methanol extracts of Salvia cryptantha (Montbret et Aucher ex Benth.) and Salvia multicaulis (Vahl)," Food Chemistry, vol. 84, no. 4, pp. 519-525, 2004. 